\title{
A visualisation tool to aid exploration of students' interactions in asynchronous online communication
}

\author{
Sujana Jyothi, Claire McAvinia*, John Keating \\ National University of Ireland Maynooth, Maynooth, Co. Kildare, Ireland
}

\section{A R T I C L E I N F O}

\section{Article history:}

Received 18 June 2010

Received in revised form

19 August 2011

Accepted 20 August 2011

\section{Keywords:}

Computer-mediated communication

Cooperative/collaborative learning

Virtual learning environments

Learning management systems

Online forums

\begin{abstract}
A B S T R A C T
Much research in recent years has focused on the introduction of virtual learning environments (VLEs) to universities, documenting practice, and sharing experience (Armitage, Browne, \& Jenkins, 2001; Browne \& Jenkins, 2003; Moron-Garcia, 2004; Weller, 2007). Attention has been directed towards the importance of online dialogue for learning as a defining feature of the VLE.

Communicative tools are an important means by which VLEs have the potential to transform learning with computers from being passive and transmissive in nature, to being active and constructivist (Pavey \& Garland, 2004). However, practical methods of reviewing and analysing online communication to trace cycles of real dialogue (and learning) have proved somewhat elusive. Qualitative methods are also underused for VLE discussions, since they demand new sets of research skills for those unfamiliar with them, and can be time intensive.

This paper describes a visualisation tool to aid the analysis of online communication. The tool has two purposes: first, it can be used on a day-to-day basis by teachers or forum moderators to review the development of a discussion and to support appropriate interventions. Second, the tool can support research activities since the visualisations generated provide the basis for further qualitative and quantitative analysis of online dialogue.

The visualisation software is designed to encode interaction types simply and quickly. The software was tested and then used to analyse data from a sample of forums within the Moodle VLE. The paper discusses both the method of visualisation and analysis of the online interactions as a pilot for further research analysing interaction in discussion forums.
\end{abstract}

(c) 2011 Elsevier Ltd. All rights reserved.

\section{Introduction}

In this paper we present a visualisation tool to support the analysis of student dialogue in asynchronous discussion forums. We propose that this tool, aside from providing a visual representation of an online discussion, can also analyse the extent of involvement of the participants, thereby giving a detailed picture of the communication pattern. This tool can help teachers or moderators to intervene in the discussion if necessary, changing the participants' focus and activity. Furthermore, the visualisations generated can support deeper analysis, including qualitative and quantitative research, into student learning in online discussion forums. An expanded toolkit for the analysis of online discussion forums would enable researchers to address the wider research question of whether and how people learn from asynchronous discussion forums, such as those provided in virtual learning environments/learning management systems (VLEs/LMSs). We argue that the visualisation software presented here supports more detailed and reliable analysis of forum messages, and therefore represents a valuable addition to the available tools and methods.

Almost all (HEIs) in the UK and Ireland have institutional VLEs (Browne \& Jenkins, 2003; Weller, 2007). Although definitions differ, VLE in this context is the label given to a system that can store teaching materials, readings, web-based resources and course information shared between staff and students in different courses of study. In addition, VLEs commonly provide tools to support online activities including quizzes, assessments, communication between students, and between students and lecturers, and some tools in support of groupwork (e.g.

\footnotetext{
* Corresponding author. Tel.: +3531708 6287; fax: +35317083520.

E-mail address: claire.mcavinia@nuim.ie (C. McAvinia).
} 
virtual presentation spaces, collaborative writing spaces, wikis and blogs). Blackboard/WebCT (http://www.blackboard.com), Moodle (http://www.moodle.org/), and Sakai (http://sakaiproject.org/) are amongst the most widely used VLEs currently. VLEs provide the means to support learning in practical ways associated with information and content management, but also have the potential to offer transformative approaches to teaching and learning, facilitating synchronous and asynchronous dialogue between participants and their teachers.

Much has been made of the potential for VLEs to facilitate online dialogue. If learning is viewed as socially situated in nature (Lave \& Wenger, 2002; Lea \& Nicoll, 2002), then dialogue becomes an important means by which meaning is negotiated and knowledge constructed. However, research examining the effectiveness of computers in education has frequently identified examples of where computers (and latterly the web) have supported a somewhat transmissive approach to learning and teaching (Pavey \& Garland, 2004). Laurillard's (1993, 2001) conversational framework, drawing extensively on educational theory, proposed that technologies should foster dialogue between teachers and students, and between students themselves, so that dialogic processes were supported, and knowledge was coconstructed. While research in e-learning has yielded good examples of how communication tools in VLEs have enhanced or indeed radically altered teaching in a range of subjects (Herrington, Oliver, \& Reeves, 2003), these cases tend to be exceptional rather than general experiences. More recently, Goodfellow and Hewling (2005) have questioned whether participation in online forums can be said to demonstrate learning. The research question arises as to whether VLE forums are fit for the purpose of supporting the conversational model of learning proposed by Laurillard $(1993,2001)$. Additional analytical tools are needed in order to address this question. In terms of practical day-to-day activities, VLEs lack tools to facilitate quick and clean overviews of busy forums. Finding time to navigate and review large numbers of discussion threads in which there is frequent activity is a well-documented problem for teachers using VLEs (Fitzgibbon \& Jones, 2004; Hamuy \& Galaz, 2010; Karasavvidis, 2009).

This paper describes the design and implementation of a diagnostic tool which provides simple visual representations of the exchanges in asynchronous discussion forum threads. The visual representation is shown within a webpage, with hyperlinked nodes displaying the body text of messages posted to discussion forums. These graphical images might assist a teacher or moderator to intervene in the discussions whenever necessary, and the visual representations of online discussions can support researchers undertaking further analysis. Two of the authors (Jyothi, Keating) were involved in the technical development of the software, while the third (McAvinia) is a learning technologist supporting staff and students using Moodle. In collaboration we were able to test this software with a sample of moderated and unmoderated forum exchanges from Moodle, for four courses at undergraduate level in Humanities subjects and one e-moderation course for lecturers (co-ordinated by McAvinia). We will discuss our initial findings in terms of the usefulness of the software as an analytical tool, and in terms of some preliminary observations about student learning. We consider what the visual analysis of the forum threads might show about the effects of moderation by online tutors in each subject. Finally, we describe the current development and future testing of this software.

\section{Research context and rationale}

\subsection{Institutional context}

The authors are all located at NUI Maynooth in Ireland, and this research was prompted by our interest in exploring some of the effects of the introduction of an institution-wide VLE at the university. NUI Maynooth has three Faculties encompassing Humanities, Social Sciences, Science and Engineering subjects. It has a student population of just over 8000. Courses at undergraduate and postgraduate levels are modular, and teaching is predominantly face-to-face, through lectures, tutorials and practical sessions. Most students are full-time participants in undergraduate courses which they attend on campus. Attendance at timetabled teaching events is expected. However, there is increasing interest in blending this 'traditional' teaching model with other modes of teaching and learning: changes in the student body, with increasing numbers of part-time and international students, are leading to greater use of learning technologies. The university adopted Moodle as its institutional virtual learning environment in 2005. In common with many VLEs, Moodle provides tools for content presentation, storage and management. It also offers discussion forums, chat rooms, instant messaging, assignment and quiz tools, course wikis and individual student blogs. All taught modules automatically have a space created for them in Moodle, with students having access to these spaces automatically after registration. The decision whether or not to use the VLE remains with lecturers and tutors and with their departments. Additional Moodle spaces have been created for staff in the Library and in offices undertaking learning support, career development and staff development activities. There are around 8000 independent student logins each week, and student use of the system is now pervasive. Patterns of VLE adoption are broadly similar to those of other institutions (Kirkup \& Kirkwood, 2005; Smith, 2005), with the initial drive being towards support for existing processes (in particular, the sharing of course materials) rather than changes to learning and teaching.

Evaluation of the use of Moodle in its first four years had been undertaken, and prompted us to undertake this research to explore the use of forums. The evaluation data from students and staff had shown that the reported benefits to students of using Moodle were predominantly practical, and related to the availability of course materials online. However, the students' responses also indicated extensive use of the Forums within their courses. One unexpected finding was the extent to which students used unmoderated Forums in Moodle. News Forum spaces (created by default in each course space in Moodle) have been used independently by students to discuss coursework, assessment and other issues. This unmoderated use of Forums in Moodle predated the popularity of social networking sites such as Facebook (http://www.facebook.com). The evaluation data suggested that students valued both moderated and unmoderated discussions. The use of unmoderated forums, in particular, was interesting as a possible site for informal learning. Therefore, we decided to explore further the interactions taking place in both moderated and unmoderated forums, and to examine whether these forums were potential supports for learning.

\subsection{The role of computer-mediated asynchronous communication in learning}

Asynchronous communication or computer-mediated communication (CMC) has been the subject of extensive research from different perspectives (Bratitsis \& Dimitracopoulou, 2008; Gant, 2007). Much of this research has focused on the use of online communication to 
foster social interaction (Berlanga, Rusman, Bitter-Rijpkema, \& Sloep, 2009; Guan, Tregonning, \& Keenan, 2008; Scheuermann, Larsson, \& Toto, 2003), to create a collaborative online environment (Scheuermann et al., 2003) and to support learning (Garrison, Anderson, \& Archer, 2001; Scheuermann et al., 2003). CMC can offer opportunities to 'meet' online when face-to-face meetings are not possible, but can also have advantages over face-to-face meetings in providing extra space and time for people to contribute to a discussion. Some learners may also be more comfortable with contributing to an online discussion than they are with speaking in a classroom.

Participants in CMC form a community where they engage in discussion and begin to share and learn more about a particular domain of interest. Such communities according to Weber (2004) are called 'episodic communities' unlike the 'communities of practice' defined by Lave and Wenger (2002). The participants meet online and learn and share information of interest. Others have dubbed them 'ad-hoc transient communities' in the context of networked learning (Sloep, 2008). In relation to VLEs and CMC, Laurillard's (1993, 2001) 'conversational framework' is frequently cited and informs course design for many practitioners building communication tools into their VLE spaces. CMC promotes a type of interaction that is often lacking in the traditional classroom. It allows learners the freedom to explore alternative pathways, and to find and develop their own style of learning (Berge \& Collins, 1995). CMC systems allow learners to interact with one another over time and promote collaborative learning. Thus, many educational institutions have sought to exploit opportunities for CMC within their VLEs. Apart from accessing course materials, students can discuss their courses in online forums and thus share their views, ask questions and gather information. In Moodle, all interactions and exchanges between people and resources are recorded and available for constant review.

\section{Analysing asynchronous discussions in online environments}

Given the importance ascribed to dialogue and CMC in educational theory, it follows that a means of reviewing and potentially analysing CMC interactions would therefore be useful to teachers and researchers, and research would benefit from an evidence base showing that online interactions had positive effects on students' learning. However, the best ways of analysing CMC are not clear. Studies that have analysed the content of the online discussions are also limited. This may be due to the time required to perform such analyses (Hara, Bonk, \& Angeli, 2000) and the lack of a reliable instrument or an analytical framework to analyse the online discussions. As Goodyear (2001) notes:

Analysing the content of networked learning discussions is a troublesome research area and several commentators have remarked on the difficulty of connecting online texts to discourse to learning. (Goodyear, cited Mehanna 2004: 283)

Although there is existing research in computer-supported collaborative learning (CSCL) and CMC which references educational theory and analyses activities in online forums (Dillenbourg, 1999), it remains difficult for practitioners to review VLE forums easily and to conduct their own analyses. Forums are often unwieldy to navigate and review, and there is no ready-made feature to analyse forum messages. Therefore, there is an immediate practical problem of reviewing progress on a daily basis, and in research terms it is difficult to apply theories about online interactions to real-world practice.

Formal assessment offers one indication of students' learning, and online dialogue may then be argued to have supported this. However, unless the method of assessment includes the forum discussion in some way, it is not usually clear where and how learning in forums may have happened. Course feedback and evaluation mechanisms, similarly, may highlight the use of discussion forums as a useful supplement or yield examples of how students have used them, but 'use' cannot be equated with learning. Some researchers have instead proposed treating forum messages as qualitative data, and thereby draw on qualitative methods for analysis. These could include broad thematic analyses or the use of Grounded Theory (Alsop \& Tompsett, 2002). Alternatively, forum messages might be treated as 'discourse', and discourse analysis or methods of linguistic analysis used (Brown \& Yule, 1983; Smith \& Oliver, 2001). Viewed from these perspectives, students' learning is related to the quantity and quality of postings in the online discussions and to the value instructors place on them (Jiang \& Ting, 2000). Henri (1992) proposes an analytical framework to categorise five dimensions of the learning process evident in electronic messages: student participation, interaction patterns, social cues, cognitive skills and depth of processing, and meta-cognitive skills and knowledge. Interactivity models, too, can be used to evaluate and interpret each of these areas individually in online learning environments.

Practitioners seeking to examine, and potentially research their students' learning in forums lack tools to map those discussions in the first instance. Qualitative research (even if it is assumed that this is appropriate to the analysis of forum messages) entails a range of tasks and processes that are potentially difficult and time-consuming to undertake and complete. Such methods may also be unfamiliar to people outside certain subject disciplines. Even for people accustomed to using qualitative methods as part of their research activities, they may be time-consuming to use in the context of evaluating learning in CMC. The methodological difficulties of analysing discussion forum data are therefore compounded by the practical constraints of time and experience. These issues have wider implications for the evidence base in elearning: it is difficult to build up case studies of appropriate and effective use of technology to enhance learning, where practitioners lack the tools to make these studies.

\subsection{Visualisation tools for analysing asynchronous discussions}

Visualisation tools (Gibbs, Olexa, \& Bernas, 2006; Kurkowski, 2009; Smith \& Fiore, 2001) appear to offer potential in providing a practical overview of forum messages easily. Visualisation allows us to generate initial analytical pictures of multiple forum threads quickly. This in turn has the potential to facilitate investigation of different sections of dialogue by looking at their visual patterns, and to guide the selection of appropriate qualitative methods for further analysis. A suitable visual tool would potentially be very useful for teachers and moderators to gauge the participation of learners in a forum, and form an impression of potential learning by looking at participation and interaction patterns. Such a tool might in turn support the development of a research design for those wishing to analyse online interactions in greater depth. However, finding a suitable visualisation tool is somewhat challenging.

Although a number of visualisation systems have been designed to process CMC, not all follow the same approach or share the same goal. One of the important challenges of the concept of visualisation is to present as much information as possible in a given display area without overloading either the display, or the cognitive capability of the person viewing. Having reviewed thoroughly the existing tools, we argue 
that this challenge has not yet been met with any of those developed so far. Fig. 1 below provides an overview of these systems, and their characteristics.

May, George, and Prevot (2007, 2008) visualised user communication activities through a web-based Tracking System named TrAVis (Tracking Data Analysis and Visualization). Welser, Gleave, Fisher, and Smith (2007) in their work describe visual strategies that illustrate patterns of contribution that they propose are a proxy for indicators of social roles (patterned characteristics of communication). Mazza and Botturi (2007) use GISMO (Graphical Interactive Student Monitoring Tool) as a graphical student monitoring and tracking tool. Mazza and Dimitrova (2004) developed CourseViz, which gives information about the active and the inactive participants, the cognitive and behavioural aspects of learners. Sheridan and Witherden (2007) explain how a visualisation application when applied to the database of a VLE could provide a quick and accurate reading of the success of a discussion using PieSpy. Figueira and Laranjeiro (2007) used iGraphs, a graphical representation to describe and obtain a descriptive image of forum participation. Gibbs et al. (2006) used software called MTRDS (Mapping Temporal Relations of Discussions Software) to analyse the temporal aspects of the online discussions. A formative assessment process of mapping discussions to analyse group interaction is described by Frey, Sass, and Alman (2006). DIAS (Discussion Interaction Analysis System) is software for monitoring and analysing interaction developed by Bratitsis and Dimitracopoulou (2008). Mohamed, Ferguson, MacCormick and Elsweiler (2004) proposed an architecture which visualises and examines the development of conversations within a bulletin board. Erickson, Halverson, Kellogg, and Laff (2002) introduced Babble which is an online conversation area that enables visual feedback of the usage patterns of the online participants and their activities. Lam and Donath (2005) proposed motion using seascape and volcano to explore large-scale discussion visualisation. Mark and Andrew (2001), describe a collection of visualisation components that illustrate patterns of activity and conversational structure using Netscan.

All of these tools are different, and have their own advantages and disadvantages. Almost all of them will generate visualisations of a single discussion thread or a single participant interaction. However, when made to show chains of messages, they become unclear and cluttered. Most visualisation tools depict crosslinks (cluttering) when describing the message chains. There is an overlap in the nodes which represent the participants, or a series of arcs which denote the flow of messages, crossing one over the other. Crosslinks and/or cluttering usually occur when the data to represent the ongoing interaction is vast. A further issue with visualisation tools is their inconsistency in terms of the criteria or 'indicators' they use in order to produce visual representations of data.

Because of these issues, it is important to clarify here where such 'indicators' come from, and which were prioritised in the development of our software. May et al. (2007) state that the traces of the learners' activities are potentially a source of information that reveals not only their activities but also various results of those activities. Donath, Karahalios, and Viegas (1999) showed that the information derived from these interactions helps learners and moderators review their own behaviour and that of others. By analysing traces of activities in collaborative learning environments, moderators could evaluate the social and cognitive behaviours of the learners. Evidence of a similar approach can be found in research of Mazza \& Dimitrova (2004), where teachers/moderators could view the three main aspects of online learners' behaviour: social, behavioural and cognitive. The indicators used in our software elaborate these three main features.

\begin{tabular}{|c|c|c|c|c|c|c|c|c|c|c|c|}
\hline Tools Indicators & $\begin{array}{l}\text { Change in } \\
\text { Subject title }\end{array}$ & $\begin{array}{c}\text { Type of } \\
\text { Interaction }\end{array}$ & $\begin{array}{l}\text { Quantitative } \\
\text { Method }\end{array}$ & $\begin{array}{l}\text { Participation } \\
\text { Level }\end{array}$ & $\begin{array}{c}\text { Social } \\
\text { Interaction }\end{array}$ & $\begin{array}{l}\text { Qualitative } \\
\text { Method } \\
\text { (Content } \\
\text { analysis) }\end{array}$ & $\begin{array}{l}\text { Cognitive } \\
\text { Presence } \\
\text { (Critical } \\
\text { Thinking) }\end{array}$ & Lurkers & $\begin{array}{l}\text { Participant } \\
\text { Details }\end{array}$ & $\begin{array}{c}\text { Time } \\
\text { Duration } \\
\text { indication }\end{array}$ & $\begin{array}{l}\text { Presence of. } \\
\text { a moderator }\end{array}$ \\
\hline $\begin{array}{l}\text { TrAVis (Tracking } \\
\text { Data Analysis and } \\
\text { Visualisation) }\end{array}$ & & & & & & & & $\checkmark$ & & & \\
\hline $\begin{array}{c}\text { Authorline } \\
\text { Visualisation }\end{array}$ & & & & $\checkmark$ & $\sqrt{ }$ & $\sqrt{ }$ & & & & & \\
\hline GISMO & & & & $\sqrt{ }$ & $\sqrt{ }$ & $\sqrt{ }$ & $\sqrt{ }$ & & & & \\
\hline CourseViz & & & & $\sqrt{ }$ & $\sqrt{ }$ & $\sqrt{ }$ & $\sqrt{ }$ & & & $\sqrt{ }$ & $\sqrt{ }$ \\
\hline PieSpy & & & & & & & & & & & \\
\hline $\begin{array}{l}\text { Representation } \\
\text { through iGraph }\end{array}$ & & & & & & & & & & & \\
\hline $\begin{array}{l}\text { MTRDS (Mapping } \\
\text { Temporal Relations } \\
\text { of Discussions } \\
\text { Software) }\end{array}$ & & & & & & & & & & & \\
\hline $\begin{array}{l}\text { DBAT (Discussion } \\
\text { Board Analysis Tool) }\end{array}$ & & & & & & & 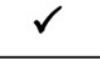 & & $\checkmark$ & & \\
\hline $\begin{array}{c}\text { DIAS (Discussion } \\
\text { Interaction Analysis } \\
\text { System) }\end{array}$ & & & & & & & & & & & \\
\hline BulB & & & & & & & & & & & \\
\hline Babble & & & & $\checkmark$ & & & & & & & \\
\hline $\begin{array}{l}\text { Seascape and } \\
\text { Valcano }\end{array}$ & & & & $\sqrt{ }$ & $\sqrt{ }$ & & & & & $v$ & \\
\hline The Netscan & & & & $\checkmark$ & & & & & $\checkmark$ & & \\
\hline VIMS & & & & & & & $\mathscr{L}$ & & & & \\
\hline
\end{tabular}

Fig. 1. A comparison of the available visualisation tools, including our VIMS tool. 
Other very commonly used indicators in the visual representation of any CMC are type of analysis, participation level, and presence of social interaction. Not many visual tools give importance to lurkers, participation details, time duration and cognitive presence. Many researchers who have developed visual tools for the analysis of online discussions talk about the importance of a moderator or instructor, but only one of them includes that indicator in the visualisation tool. Change of topic and type of interactions (explicit or implicit), though important are not indicated in any of the visual tools.

The last row of the table shown at Fig. 1 relates to the software we have developed, entitled Virtual Interaction Mapping System, or VIMS. Although VIMS shares some of the features of some of the models mentioned earlier, it differs in that it provides an automated dynamic uncluttered visualisation, and it can be embedded into the VLE. It is constantly updated with new postings to the Forum. It also includes moderator/tutor messages. This gives the instructor a representation that attempts to convey a sense of the participants' behaviour and gives an insight of the flow of conversational activity. Since it is based on visualising semester-based subject-oriented discussions, it is limited to reviewing forums for a three-month period (one semester), but can be used to take 'snapshots' over shorter periods of time.

As research in this area has expanded, new indicators for example, 'Message read' indications seem to be used in the visual representations to give more insight into the ongoing conversations. Recently, Dringus and Ellis (2005) identified and emphasised the need to analyse interaction data to reveal the 'dynamics of online learning and interaction processes' and proposed common participation indicators which they think are of prime importance to assess student progress in forums. According to Dringus and Ellis, the common participation indicators are: Level of interaction in the forum, Learner-learner interaction activity, Degree of cognitive and social presence, Timing and pace, Staying on topic, Transitions, Extent of Instructor presence, Instructor-learner activity, Teaching presence, Mandatory/non-mandatory participation, Lurking, Shared resources, Accuracy of message content, Message response accuracy, and Group size. These indicators help in the visual analysis of the discussion.

As research in this field is extensive and is growing, it is likely to identify many more indicators which should be designed into visualisation tools for use with asynchronous online interactions. For our purposes, we looked for a visualisation model that included not only the key indicators identified in previous research (Fig. 1), but which had been designed with an informed approach from educational theory. The work of Schrire (2004) seemed promising in presenting a visualisation tool that looked for evidence of changes in cognition as well as interaction. The next section presents this model in further detail.

\subsection{Schrire's method of visual analysis}

The work of Schrire (2004), in organising and representing forum messages visually has provided a different perspective on the problems described earlier, and potentially connects the initial mapping provided by visualisation tools with further analysis of online interactions. We drew on this work to inform the development of our visualisation tool as a means of both mapping and analysing forum discussions.

In tandem with a visual model using specific indicators, Schrire proposes a model of analysis which looks for evidence of links between cognition and interaction, rather than focussing on the linguistic or thematic aspects of discussion messages. Schrire analyses asynchronous discussion for evidence of 'interaction and cognition' (2004: 475). Drawing on a range of theoretical models, she asks three research questions:

1. What patterns of interaction can be found in asynchronous online computer conferences?

2. What kinds and levels of individual and socially distributed cognition characterise the learning process in asynchronous online computer conferences and their component threads?

3. How are interaction and cognition connected in asynchronous online computer conferences? (2004: 481)

Her analysis is framed firstly by the visual representation of the discussion, and then by three theoretical approaches:

1. Bloom's taxonomy (Bloom, Engelhart, Furst, Hill, \& Krathwohl, 1956): focussing on the evidence for analysis, synthesis and evaluation associated with the upper levels of Bloom's taxonomy.

2. The SOLO taxonomy (Biggs \& Collis, 1982): Structure of Observed Learning Outcomes: analysing the discussions using a taxonomy designed to show whether there had been in-depth or surface learning.

3. The Practical Enquiry Model of Cognitive Presence (Garrison et al., 2001): identifying collaborative construction of knowledge in asynchronous forums, and looking for evidence of community amongst learners, rather than evidence of a more 'practical' focus in using asynchronous discussion (e.g. for course management or information).

Taking a case study design, Schrire developed a paper-based visual representation of asynchronous forums (which she terms computer conferences). This 'interaction pattern mapping' gives a visual representation of the discussion threads making up the conference, the clusters of messages interacting with one another around sub-topics of the conference.

The entire discussion is first read from beginning to end in order to get a general impression of the conversation. Each message is then visually depicted as a circle, and accorded a number based on its position in the chronology of the conference. Instructor messages are differentiated from students' messages by using different colour schemes. Message connections, showing the direction of the interaction, are represented by arrows. A dotted line is used when interaction is possibly present, but could not be established definitively. Message clusters, that is, messages interacting around a subtopic of the discussion, are shown as such on the interaction pattern map.

Once constructed, the interaction pattern map can be scanned for important details, such as the intensity of activity in the component threads, the presence of distributed versus 'centralised' interaction, messages that have become nodes of interaction, and messages that are unanswered or that have remained isolated in the discussion space. Important or distinctive features become apparent from the interaction pattern map: it becomes very clear that threads are interactive to a greater or lesser extent, and also whether the interactions are one-way only or multi-directional. In Schrire's analysis, the interaction pattern maps allow her to categorise threads into five interaction pattern types: 
1. Instructor-centred: responses initiated and triggered by the instructor message and responding mainly to the instructor message.

2. Synergistic: responses to the initiating message as well as follow-ups by conference participants from one message to another. Interactions where every message is connected to another, either directly or indirectly.

3. Developing synergism: Mixed characteristics of Instructor-centred and Synergistic interactions.

4. Scattered: small separate message clusters around loosely related sub-topics.

5. Student-centred: responses initiated by a student message.

Schrire's framework for analysis proposes that the more synergistic the patterns, the greater the support to claim that knowledge is being co-constructed by learners and teachers in the online forum.

\section{Methods for the design and testing of VIMS}

We explored the possibility that VIMS could be designed to enhance Schrire's model by producing a dynamic visual 'interaction pattern map', but also including a way to access the content of messages in order to support the analysis of forum interactions. The objective was to produce the maps simply, in an online format through which messages remained available, and without the need for extensive paper-based sketching and encoding before review or analysis of a discussion thread could take place. Schrire's visualisations showed a very simple and concise representation, giving a clear picture of the interaction patterns for all the discussion threads in a forum, within a specific boundary. We chose a radial tree structure (Sheth \& Cai, 2003) to represent the asynchronous discussion as it is a simple way to show perceptual organisation. Using a circular arrangement of tree nodes, we could represent the whole tree as a structure of nested circles, showing the degree of student participation.

VIMS provides real-time, radial-tree visualisation of the forum interactions, realised using a combination of SVG (Scalable Vector Graphics) using Perl with JavaScript. Visualisation maps are presented as interactive scalable images, viewable using most web browsers; the version described here can be seamlessly incorporated into Moodle. The technologies combined in VIMS allow the visualisation to have 'hot spots', on which the mouse can hover to access full details of a message. There is a continuous link between the image and the web server, implemented using AJAX, which means that the visualisation will change according as new messages are sent to the forum. An algorithm within the software depicts borders, differentiating between the threads of a discussion forum.

\subsection{Initial tests}

Figs. 2 and 3 show the initial test visualisations we produced. Two forums are shown, each having four threads. Fig. 2 shows a moderated Forum, Fig. 3 an unmoderated Forum. Following Schrire's method, the entire discussion was first read to get a general impression of the conversation. Then, VIMS was applied to the data, to produce the visualisations shown here. The messages posted by the participants are represented as circles and the arrows connecting them represented the dialogue between those connected participants, flowing in the direction of the arrowhead. The message text can be viewed by placing the cursor over the message-flow arrow. The instructor can also view the profile of the student with a click on the node that represents that student. This gives a detailed description and shows the involvement of the student.

The interactions are depicted in layers: the person starting the thread is placed at the centre (the first level), and the people responding to the thread are placed at different levels around it. The presence of the node on the farthest circle (of each thread) indicates its level and depth in the structure. The depth and the number of levels represent the complexity of the discussion thread, and are explicitly clear from this structural layout. The arrow between the two nodes represents the flow of information (the message). For example, an arrow from one node in level2 connected to another node in level1 with the arrowhead (always) facing to the lower levelled node (level1), indicates that the

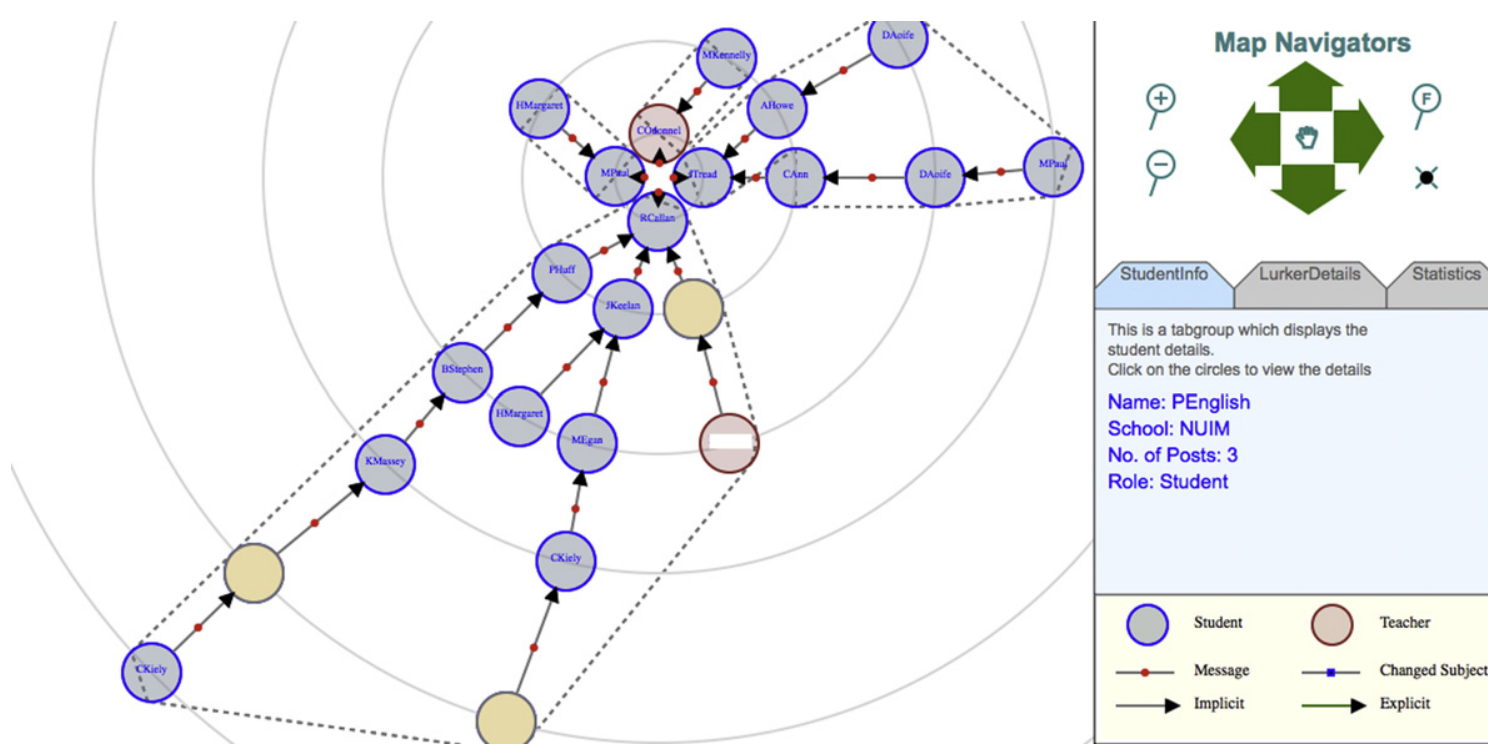

Fig. 2. Initial test, threads from a moderated forum. 

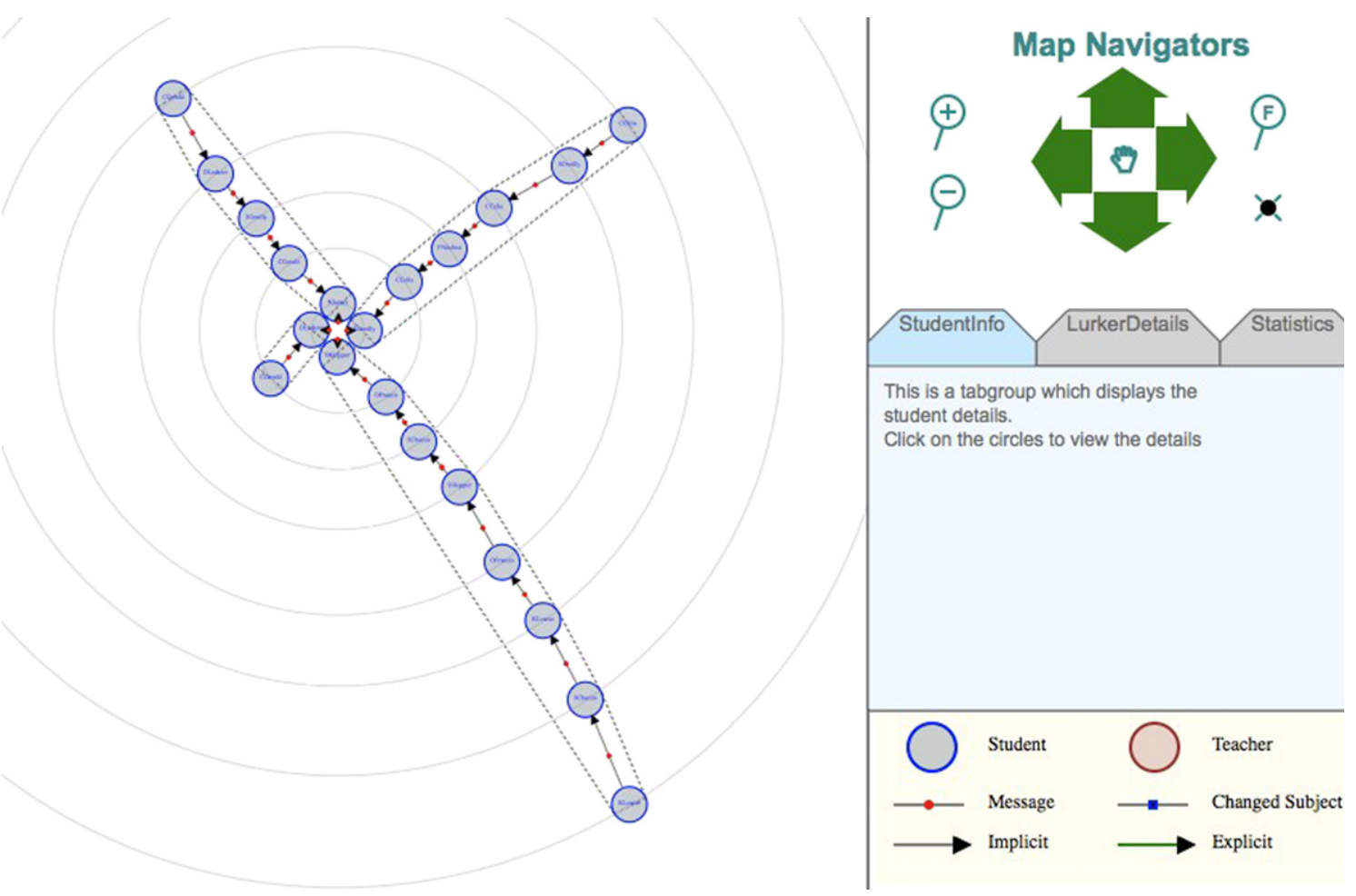

Fig. 3. Initial test, threads from an unmoderated forum.

participant at level2 is responding to the participant at level1. If there are more than one nodes with arrows pointing to a node at a lower level, this implies that there were more respondents to that post. The arrowheads with a dot in the nodes at the first level are used to view the post of the initiators.

While time and timing are implicitly part of Schrire's model, we looked for ways to make this more explicit in VIMS. Although asynchronous discussions are by definition taking place at different times and places, it is important to consider time and timing in the messages that result. Long gaps in discussion can indicate possible lack of understanding of material, or perhaps difficulties communicating (whether these are due to linguistic or other barriers). Drawing on Gibbs et al.'s (2006) visualisation model, we included a means for the viewer to see the hour and date of a message. The drop-down lists which are displayed on the Moodle/VLE page can be set to generate visualisations week by week. The first selection list displays the overall interactions in the forum and the second selection list visualises those conversations on a weekly basis. The moderator would then be able to identify the participation level in the discussion, and how long a particular discussion lasted.

Interaction maps produced by VIMS can be shown in greyscale or colour. Colour-coding supports quicker and more efficient reading of the visualisation. For example, a red node can be used to represent teacher/moderator, and a blue node can represent a student participant. Dotted lines and arrows can show a deviation from the topic under discussion. A dot on the arrow used within the radial tree means that the message details are available on clicking. A change of subject heading in a message is shown by a blue square. The concentric circles show the levels of the discussion, with the number of levels indicating the depth of the discussion. The dotted outline surrounding a set of circles represents a boundary around a particular thread within the discussion which distinguishes every discussion thread in a forum. (The learners interacting in one thread are separated from the other threads by drawing boundaries using the convex-hull algorithm.) We wanted to distinguish every discussion thread in a forum with a boundary and so included the concept of convex-hull. In computational geometry, "convex hull" is defined as the boundary of the minimal convex set containing a given non-empty finite set of points in the plane (Gries \& Stojmenovic, 1987). It helps to easily identify the depth (number of levels) and the width (responses at a particular level) of the structural layout easily. The more depth and width, the greater is the learning impact (Schrire, 2006). The boundary or time limit of the visualisation of a particular thread would be three months (one semester), but can be set to a shorter time frame within that period. Tabs located to the right of the visualisation show the details of the participant, lurkers, and other statistics about the forum (total number of posts, views, participants, threads, lurkers; the average number of posts per participant, average number of views of a typical discussion and average number of words per message). In greyscale, shades of black and grey as well as the existing symbols and lines, are used to generate the visualisation.

Having completed the initial technical testing, and confident that the tool was technically viable, we then carried out a more structured sampling of moderated Forums, selecting three threads for analysis:

1. Fig. 4: A thread discussing racism in the work of a particular writer, taken from a first year humanities course. There were 472 students registered to the course in total. Moodle had logged 2887 records for the overall discussion, which included two other threads. These other threads were barely used, and so the activity was predominantly in the thread we sampled. There were 44 replies to the original posting by the Lecturer. 32 people participated in the thread, but the logs reveal that 235 people accessed and viewed the discussion 


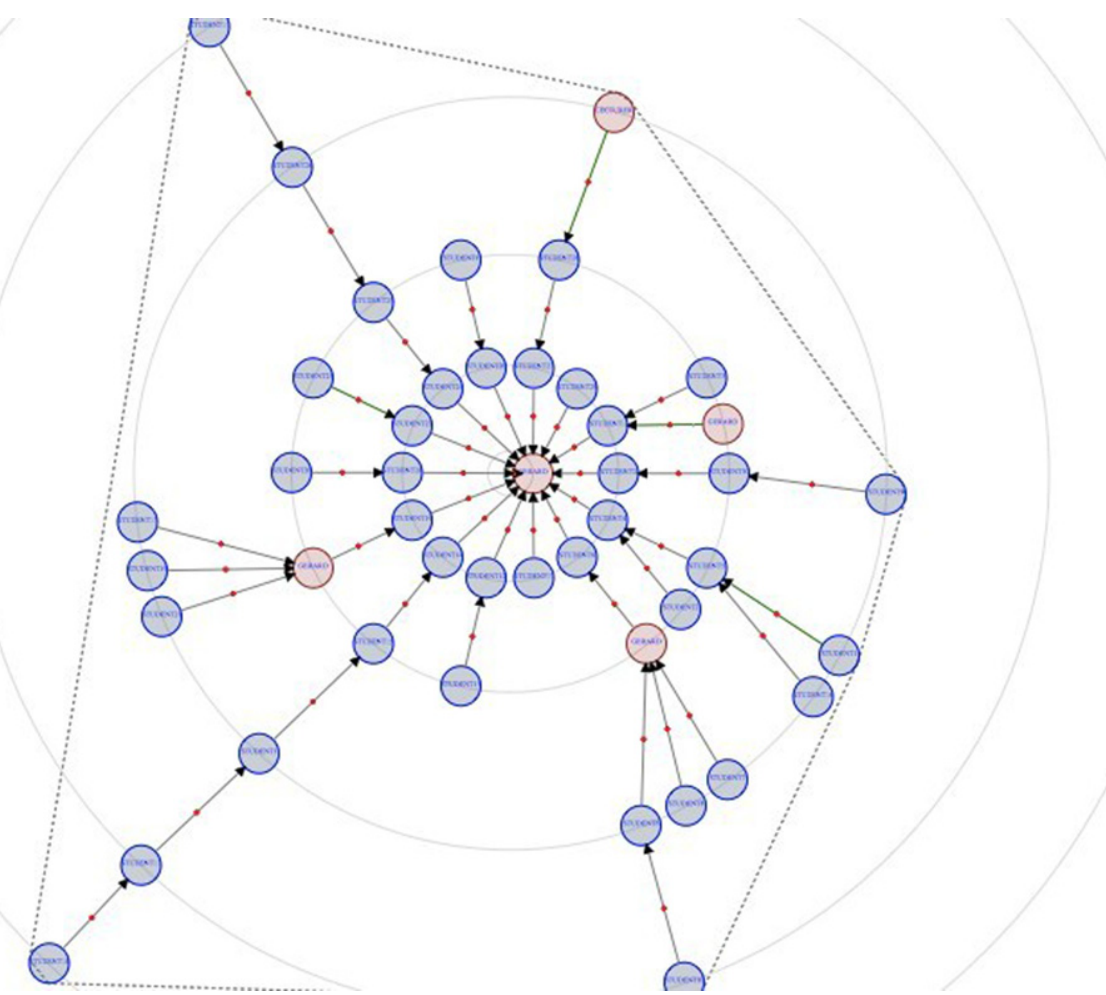

Fig. 4. Discussion of thread concerning whether writer was racist.

from its launch date until mid-summer (when all examinations would have been completed). Therefore, there were 203 people 'lurking' in this discussion who viewed the thread at least once without posting to it. Some of these lurkers had returned several times at intervals during the discussion.

2. Fig. 5: This thread was again from a first year humanities course and addressed a specific theme in a poet's work. 473 students were registered to the course, which had a large number of Forums, one for each topic studied. There were 11 messages in the thread selected, and just four people were involved in the exchange of these messages. However, the logs showed that 128 people viewed the discussion at intervals. This means that there were 124 'lurkers' in this thread, viewing it at least once without posting any messages. But in contrast to the first thread, there were few return visits by lurkers, and they tended to view the messages once only.
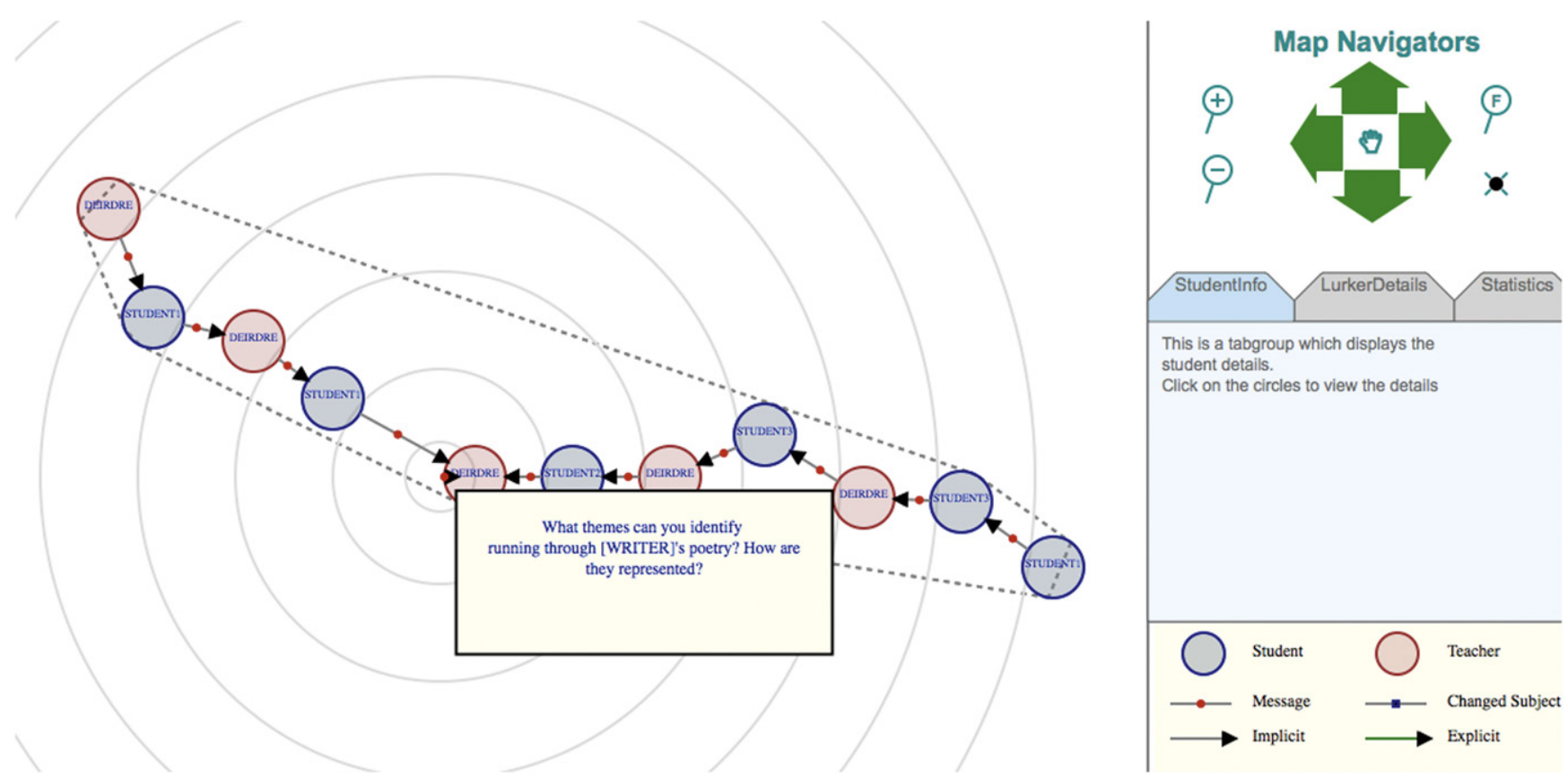

Fig. 5. Discussion thread on themes in poetry. 


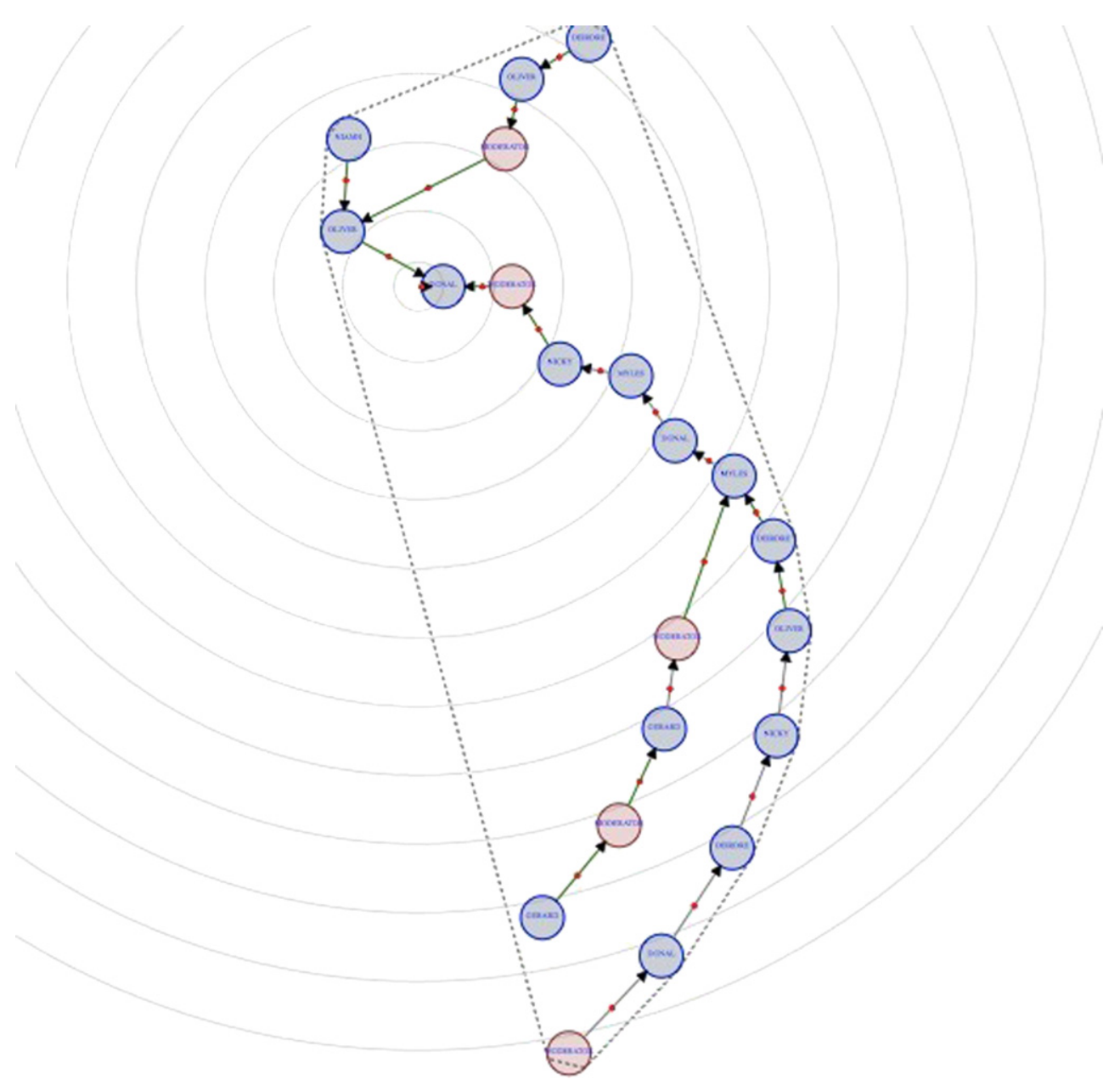

Fig. 6. Thread from online staff development course on e-moderation.

3. Fig. 6: The last thread came from an online course for lecturers and tutors. The course was designed to help staff develop skills in forum moderation, and participants attended online only. There were nine registered participants on this course, and the busiest thread was selected. It had 21 messages, and all but two of the course participants had posted to the thread, with only one person never viewing it at all.

In this phase of our research, we aimed to select threads that showed a good degree of activity, but also to include a thread which would clearly show conscious and deliberate efforts to moderate discussion in the case of the staff development course. This was to highlight the importance of the various types of interactions possible in an asynchronous environment and to represent the pattern of such interactions. However, the limitations of our samples must be acknowledged: for ethical reasons it was not possible to use large amounts of data from Moodle at this stage. Our primary concern was to protect the personal data of staff and students, and therefore we selected and extracted small amounts of data which could be easily anonymised. (However, it is well to note that VIMS can also be used with large amounts of data.)

In our initial tests, and also our subsequent analysis of three selected discussions, the threads were parsed by the software to produce interaction pattern maps. The final illustration, in Fig. 7, shows how a message would appear to the viewer where he/she hovered over the arrowhead between two of the nodes shown. In this case, the message was from 'Shauna' to 'Cormac' and refers to a book Cormac is asking about.

\section{Findings}

Following Schrire's (2004) model, we attempted to categorise the overall trend of the messages based on Schrire's scheme (from 'instructor-centred', 'synergistic' to 'student-centred' and 'scattered'). As can be seen from the visualisations reproduced here, the visual representation not only differentiates a teacher from a student but also shows if there was in the change in the subject title, and identifies an explicit and an implicit interaction. According to Henri (1992), explicit interactions are messages that are either in response to a question posted, or comment on someone's message. In explicit interaction, the person to whom the communication is directed is indicated in the message. Implicit interactions on the other hand make no reference to a previous message. Very often, people responding to a post tended to change the subject title to something relevant to their message. This change in subject title might eventually change the subject or topic of discussion. The legends (Figs. 4, 5 and 6) denote how such changes are represented visually. We can present further analysis in respect of Figs. 4, 5 and 6. 


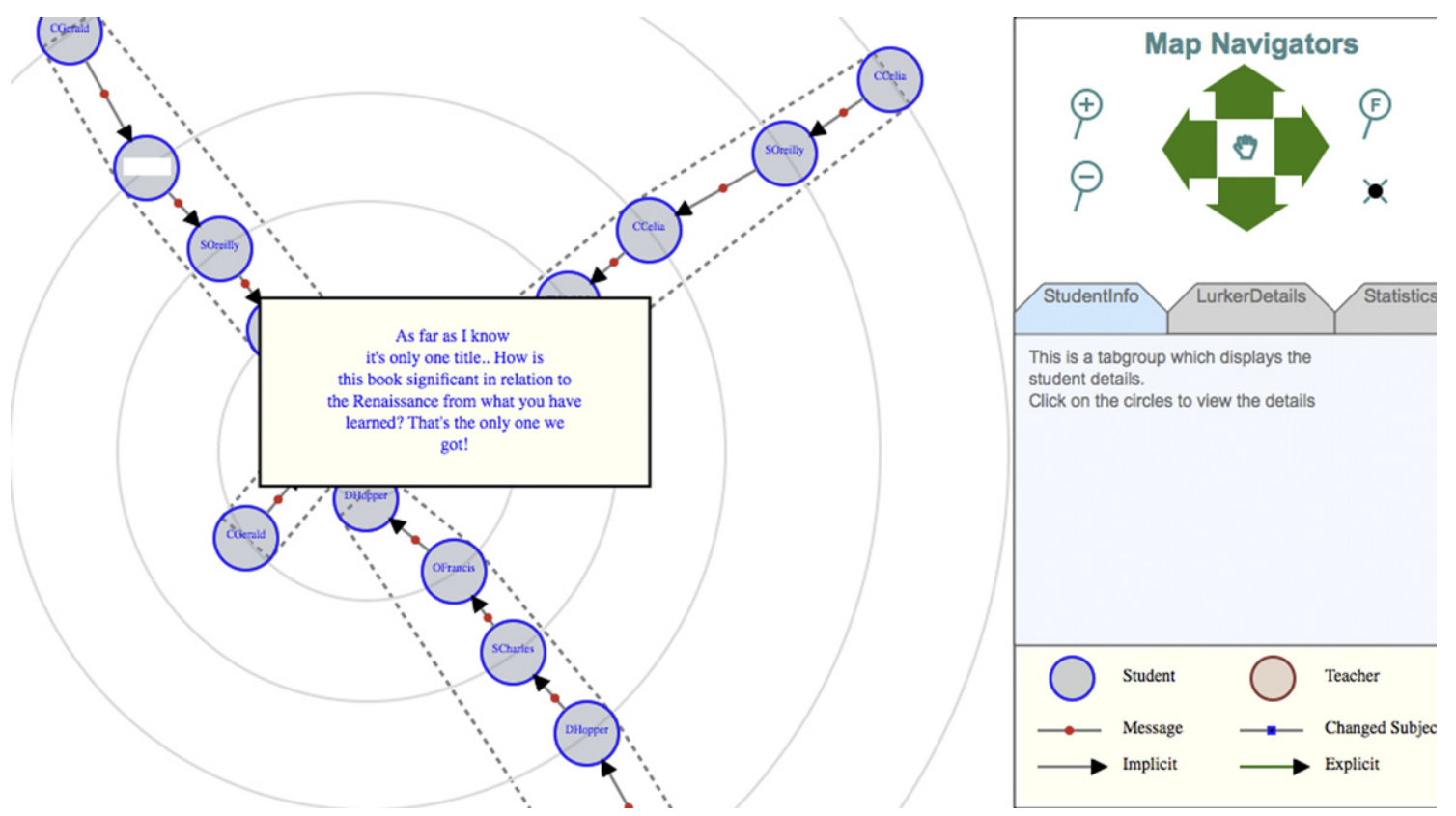

Fig. 7. Example showing how message text can be accessed from the map.

Fig. 4: This thread had been initiated by a teacher, and as such it could be regarded as Instructor-centred. Most of the students are intending to reply to the teacher's message. We also see that there are a lot of follow-up responses to the threads, and the thread shows a Synergistic pattern of interaction. The web like structure of this thread with a depth of five levels indicates collaborative learning and some social networking in this forum. The teacher has not just initiated the thread and kept silent but has responded to some of the messages which says that the teacher/moderator is performing his/her role by intervening and participating in the interaction process.

Fig. 5: In this thread we see almost the opposite scenario to that in Fig. 4. This thread is also initiated by a Lecturer, but the students did not participate in the thread to the same extent. The group size is the same as that for the thread in Fig. 4, but more Forums were used in this course. Only four people participated in this thread, and the messaging is linear in nature. We see that the teacher had to keep posting her views and asked for more ideas and thoughts on the subject to motivate the students to post more. This thread is Instructor-centred and does not appear to move towards the Synergistic pattern.

Fig. 6: Compared with the other two threads, we can say that the thread in Fig. 6 is the busiest, because of the amount of activity among only nine registered participants. All but two of the course participants posted to this thread, and only one of these people never accessed the thread at all. The other person viewed it on just one occasion. The visual representation of this thread shows Developing synergism: the Instructor contributes at several points, but there are areas in which the discussion sub-divides and is not confined to the linear pattern.

The radial tree shown in Fig. 3 indicates a linear pattern to messages, with no sub-division into discussion of the first posting. By contrast, the moderated threads represented in Figs. 4 and 6 combined 'instructor centred' dialogue with 'synergistic' dialogue. The radial tree representation suggests that there were more connections between messages in these threads. However, it is interesting to note that there is more instructor presence in Figs. 5 and 6 than in Fig. 4, where the students appear to take the discussion and develop it in a number of directions independently.

When there are more connections between messages, Schrire suggests there is more evidence of collaborative learning. The unmoderated forum shown in Fig. 3 in our test example, has what Schrire describes as the appearance of 'spokes on a wheel' with a linear messaging process rather than connections between parts of the dialogue. In the absence of synergistic dialogue, it becomes more difficult to argue that learning (or collaborative learning) is taking place. According to Schrire's classification, the unmoderated thread combines 'scattered' and 'student centred' messages. However, we also see a linear pattern in Fig. 5, which is 'instructor-centred'. We see more evidence of wider dialogue in the moderated threads in Figs. 2, 4 and 6, where the original message gives rise to two or three separate strands of discussion. The trend is towards a 'synergistic' pattern in these threads.

\section{Discussion}

The previous sections described the development and testing of this software to visualise ongoing interaction and participation in forums, along with some preliminary findings. We have argued that the VIMS software can provide a useful means of mapping discussions in the first instance. However, it also functions as an enhanced version of Schrire's (2004) model, and therefore provides an initial analysis of the interactions. This initial analysis, we argue, could support the development of a research design to undertake more detailed qualitative analysis of forum discussions. The interaction pattern maps shown earlier, and our initial findings described above, have indicated a number of areas for discussion at this stage.

In earlier local evaluations of VLE usage, the extent of the use of unmoderated forums by students was an unexpected finding. First reading of some of these unmoderated discussions suggested that they could be potentially valuable sites for learning. However, the interaction pattern map for four threads in an unmoderated Forum in which we had seen messages relating to coursework and course reading (Fig. 3) suggested it was student-centred and even scattered in nature, with little evidence of synergistic dialogue. Having used the 
visualisation tool to examine this unmoderated discussion, we would now reconsider the focus of further research in this area: it seems less likely that unmoderated discussions are sites for collaborative learning. Therefore, the visualisation tool has had merit in helping us to refine and refocus a research question arising from the evaluative surveys previously undertaken.

We would also re-examine the role of the instructor/moderator in moderated forums. Figs. 5 and 6 show patterns that might be described as instructor-centred (Fig. 5) and instructor-centred tending towards synergistic (Fig. 6). The most synergistic discussion is seen in Figs. 2 and 4. Although an instructor is present in both Figs. 2 and 4, instructor postings are firmly in the minority compared with students' postings. In these cases, we might begin to examine why the discussions were more synergistic in nature and therefore had more potential for collaborative learning. Were the topics being discussed of greater interest or importance to students? In the case of Fig. 4, we know that the discussion focused on a potentially controversial topic, whether or not a particular writer could be regarded as racist. This clearly generated debate amongst students. However, in the case of Fig. 2, we observed something different: the instructor/moderator had made extensive use of the 'Topic' spaces in the course homepage in Moodle. These spaces - although not forum spaces - referred to the discussions, and set particular tasks for students. Topic spaces are frequently used as 'notice boards' in Moodle, and are easily updated. However, they are static and the information shown in topic spaces is not copied to forums, nor is it visible within a forum. It may or may not be read by the student before viewing forum messages. A topic space may therefore have a role - albeit limited - in influencing the discussions in a Moodle course. Here again, then, the visualisations have prompted us to reconsider and refocus possible research questions in the analysis of the online interactions. The role of the instructor/moderator has been shown to be nuanced, and potentially to be dependent on the topic under discussion, as well as the wider course space in Moodle.

Our concerns in this research have been to produce dynamic interaction maps, and to begin the process of analysing these. It was outside the scope of this preliminary research to investigate further the discussions undertaken by the groups sampled here, and there were practical constraints on how much of their discussions we could draw on. However, the findings from our initial tests and our structured samples suggest that the discussions shown in Figs. 2 and 4 would merit further research and analysis to examine the collaborative learning taking place. With a research design that also included interview or focus group work with students, it would be possible to investigate whether the discussions shown in Figs. 5 and 6 would have benefited from an alternative choice of topic, or whether practical issues (such as timetabling and assessment deadlines) influenced the extent to which learners could participate in forums. In the case of staff learners (Fig. 6), they may not have found moderator intervention useful, since they were already accustomed to working together within their academic department. Initial analysis, based on the interaction mapping, provides us with insights for further analysis, and the formulation of clearer research questions. The areas we wish to investigate further could now be examined using other qualitative and quantitative methods.

\section{Conclusions}

This paper has described and presented a tool building on the existing and extensive work undertaken by other researchers for the analysis of asynchronous discussion forums in virtual learning environments. Our piloting and evaluation of this tool suggests that it offers an appropriate and effective means of managing discussion forum messages in a visual format which then facilitates decision-making for additional in-depth analysis. The initial visual pattern suggests broad categories into which discussion threads may be falling, and offers directions for further analysis. While our examples are drawn from a limited pilot study, they have nonetheless yielded indications about how asynchronous Forums in Moodle (specifically) are used by teachers and students in a campus-based university setting.

In relation to the methodological focus of this paper, namely that researchers need an expanded toolkit for the analysis of online discussion forums, we propose that the software developed and piloted offers the ability to analyse large numbers of discussion messages quickly and comprehensively. The facility with which interaction pattern maps can be produced using VIMS should enable greater numbers of teachers to analyse CMC interactions, typically in VLE forums. The embedding of the tool within a VLE will allow anyone editing a course space to use it. VIMS is to be released as an open source tool which will be freely available to people to download and use. The visual representation benefits from a clear structure and uncluttered appearance on-screen, but retains the message text through hyperlinking to the Forums. Data can be anonymised during the parsing process. The visualisations can then be used to assess whether there was learning going on, or the formation of social network, or a combination of the two. The patterns of interaction as described by Schrire help to analyse the maps and identify patterns of collaborative learning as opposed to linear messaging. A deeper analysis of the structure and quality of the postings, will give indications of higher-order thinking and a clearer insight into collaborative learning. The instructor can also view the profile of the student with a click on the node that represents that student.

VIMS has considerable advantages as a visualisation tool. First, the discussions are shown in a systematic way, with the people starting the discussion placed at the first level. There is no on-screen clutter from message text and all threads in a discussion forum can be viewed at a glance. Navigation on-screen allows the discussion to be viewed as a whole, or for the viewer to zoom in on certain areas. One or more threads can be compared easily. This visual aid could help the instructor develop a collaborative environment, by aiding him/her to visualise the active and inactive participants, and therefore inform appropriate interventions.

It is important to acknowledge the limitations of the VIMS tool too: it is in essence a support for coding and management of the data, rather than offering in and of itself a new method for analysing that data. For such analysis, we need to consider the wider model used by Schrire or indeed to pursue existing qualitative methods. VIMS does not yet allow us a way to analyse the multi-modal nature of the student discourse in unmoderated Forums, and the inclusion of images, sounds and other media which students are now accustomed to using. This is a further area of work we need to address, but one for which the other visualisation tools described in this paper are (similarly) unsuited.

In relation to the Forums analysed here, we have found patterns indicating that collaborative learning is happening in the moderated threads. However, in the unmoderated thread and in one of the moderated threads, discussion tended towards linear messaging rather than cycles of dialogue between participants. We cannot conclusively argue that phases of critical thinking (such as those identified by Schrire) are present or absent from the threads we have analysed thus far. But we have been able to refine and refocus research questions based on the initial visualisations generated. Specifically, we have revisited our conceptions of threads as either 'moderated' or 'unmoderated'. We have identified areas for investigation depending on the extent to which a teacher is involved in the discussion. Teacher intervention did not always influence the pattern of interactions positively (according to the Schrire model). The use of 'Topic' spaces in Moodle as, in effect, 
course notice boards and news spaces also complicates the notion of moderation in a forum. We would seek to investigate further whether conventional notions of moderation (Salmon, 2000) are being problematised by the flexibility of certain areas of the Moodle VLE.

Our development of VIMS is continuing. The goal is to release VIMS as an open source project at the earliest, so that interested users can explore the usability of VIMS and researchers can expand the tool in the near future. VIMS requires some further refinement to parse Forums containing more numerous threads and threads with more numerous messages. We are exploring the possibilities for representing multimodal messages (text with graphics, voice and other media, e-mail messages) in the radial tree representation, and will continue to analyse both moderated and unmoderated asynchronous Forums in Moodle with the aid of this tool. We also plan to test the software further with teachers and students, and to evaluate their experiences using the visualisations generated. Further end-user testing will be undertaken with people using the software to support both teaching and research using online forums.

\section{Acknowledgement}

The authors wish to thank the reviewers whose detailed comments have been very valuable in the course of writing and revising this paper.

\section{References}

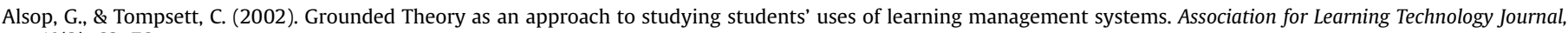
$10(2), 63-76$.

Armitage, S., Browne, T., \& Jenkins, M. (2001). Management and implementation of virtual learning environments: A UCISA funded survey. UCISA.

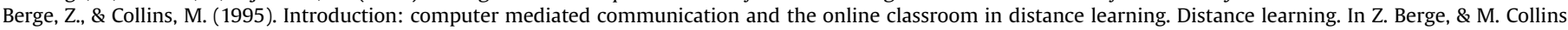
(Eds.), Computer mediated communication and the online classroom in distance learning, Vol. III. Cresskill, NJ: Hampton Press.

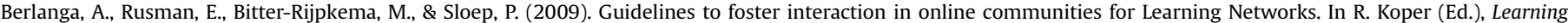
network services for professional development (pp. 27-42). Berlin, Heidelberg: Springer.

Biggs, J. B., \& Collis, K. F. (1982). Evaluating the quality of learning: The SOLO Taxonomy. New York: Academic Press.

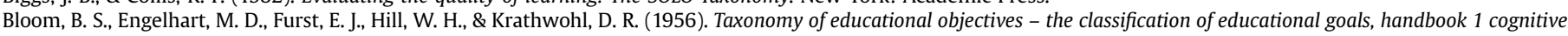
domain. London: Longman Group.

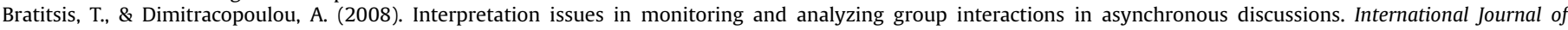
e-Collaboration (IJeC), 4(1), 20-40.

Brown, G., \& Yule, G. (1983). Discourse analysis. Cambridge: Cambridge University Press.

Browne, T., \& Jenkins, M. (2003). VLE surveys: A longitudinal perspective between March 2001 and March 2003 for higher education in the United Kingdom. UCISA.

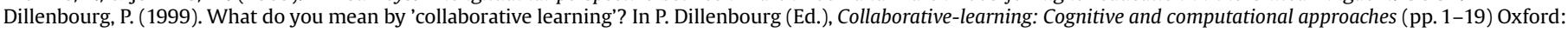
Elsevier.

Donath, J., Karahalios, K., \& Viegas, F. B. (1999). Visualizing conversation. In. Proceedings of the 32nd Annual Hawaii International Conference on System Science, Vol. 4 (4).

Dringus, L. P., \& Ellis, T. (2005). Using data mining as a strategy for assessing asynchronous discussion forums. Computers $\mathcal{E}$ Education, 45, 141-160.

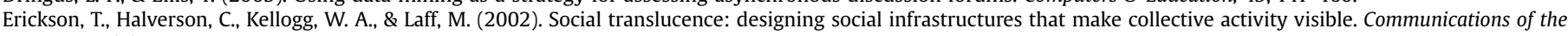
ACM, 45(4), 40-44.

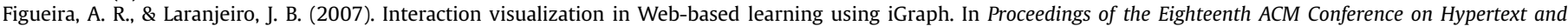
Hypermedia (pp. 45-46). New York: ACM Press.

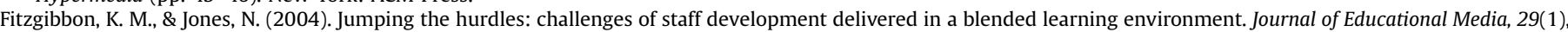
25-35.

Frey, B. A., Sass, M. S., \& Alman, S. W. (2006). Mapping MLIS asynchronous discussions. International Journal of Instructional Technology and Distance Learning, 3(1), 3-16.

Gant, C. (2007). Assessing asynchronous discussions: an exploratory hybrid model. Online Journal of Distance Learning Administration, 10(3).

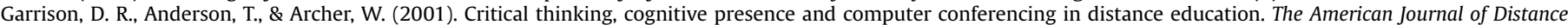
Education, 15(1), 7-23.

Gibbs, W. J., Olexa, V., \& Bernas, R. S. (2006). A visualization tool for managing and studying online communications. Educational Technology and Society, 9(3), 232-243.

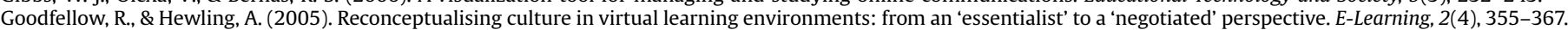

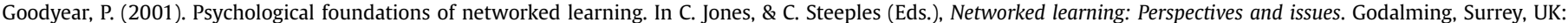
Springer.

Gries, D., \& Stojmenovic, I. (1987). A note on Graham's convex hull algorithm. Information Processing Letters, 25(5), 323-327.

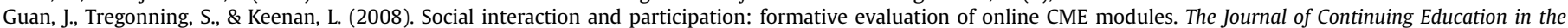
Health Professions, 28(3), 172-179.

Hamuy, E., \& Galaz, M. (2010). Information versus Communication in Course Management System participation. Computers and Education, 54, 169-177.

Hara, N., Bonk, C. J., \& Angeli, C. (2000). Content analysis of online discussions in an applied educational psychology course. Instructional Science, 28(2), 115-152.

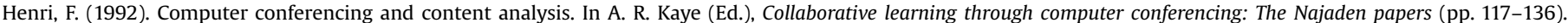
Berlin: Springer-Verlag.

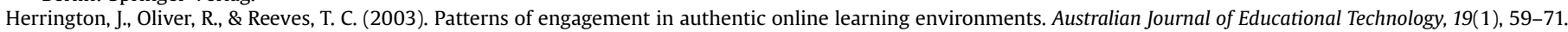

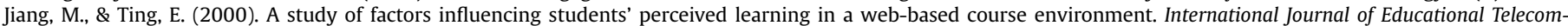
munications, 6(4), 317-338.

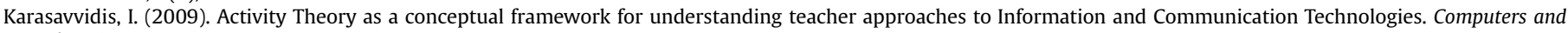
Education, 53, 436-444.

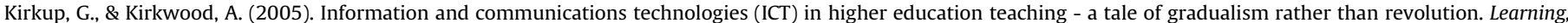
Media and Technology, 30(2), 185-199.

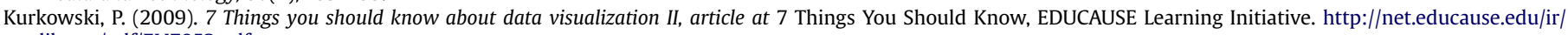
library/pdf/ELI7052.pdf.

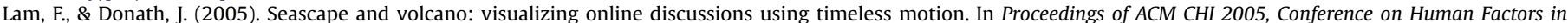
Computing Systems (pp. 1585-1588).

Laurillard, D. (1993). Rethinking university teaching: A framework for the use of educational technology. London: Routledge.

Laurillard, D. (2001). Rethinking university teaching: A conversational framework for the use of educational technology. London: Routledge.

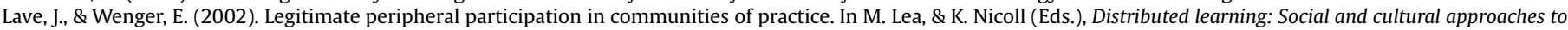
practice (pp. 56-63). London: RoutledgeFalmer.

Lea, M. R., \& Nicoll, K. (2002). Distributed learning: Social and cultural approaches to practice. London: RoutledgeFalmer.

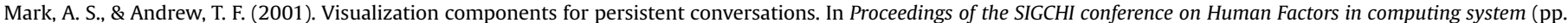
136-143).

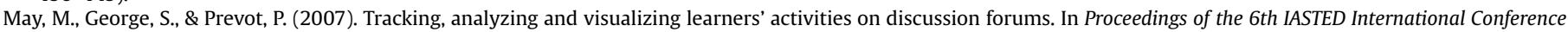
on Web-based Education (WBE) (pp. 649-656). France: WBE.

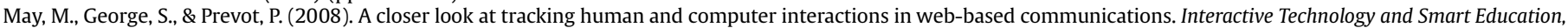
5(3), 170-188.

Mazza, R., \& Botturi, L. (2007). Monitoring an online course with the GISMO tool: a case study. Journal of Interactive Learning Research, 18(2), 251-265. 


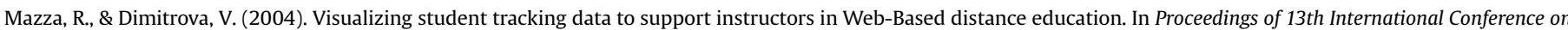
World Wide Web (pp. 154-161).

Mehanna, W. N. (2004). e-Pedagogy: the pedagogies of e-learning. Association for Learning Technology Journal (ALT-J), 12(3), $279-293$.

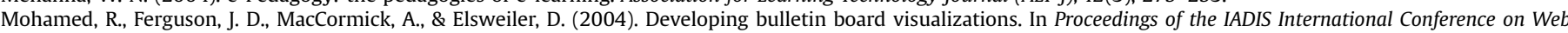
Based Communities (pp. 11-18).

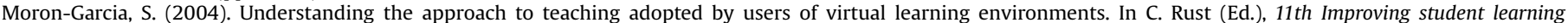
symposium: Theory research and scholarship (pp. 235-248). Oxford: Oxford Centre for Staff Development.

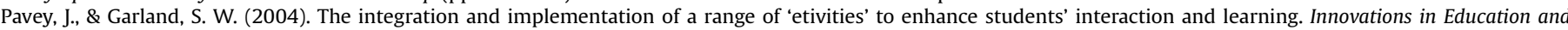
Teaching International, 41(3), 305-315.

Salmon, G. (2000). E-Moderating: The key to teaching and learning online. London: RoutledgeFalmer.

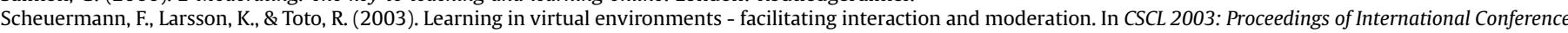
of Computer-Supported Collaborative Learning. Bergen: CSCL.

Schrire, S. (2004). Interaction and cognition in asynchronous computer conferencing. Instructional Science, 32, 475-502.

Schrire, S. (2006). Knowledge building in asynchronous discussion groups: going beyond quantitative analysis. Computers 8 Education, $46,49-70$.

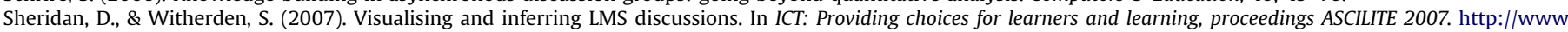
ascilite.org.au/conferences/singapore07/procs/sheridan.pdf.

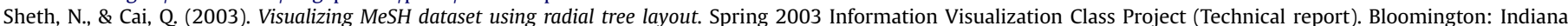
University.

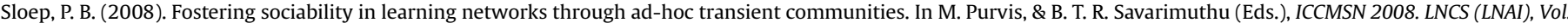
5322 (pp. 62-75). Heidelberg: Springer.

Smith, J. (2005). From flowers to palms: 40 years of policy for online learning. Association for Learning Technology Journal (ALT-J), 13(2), 93-108.

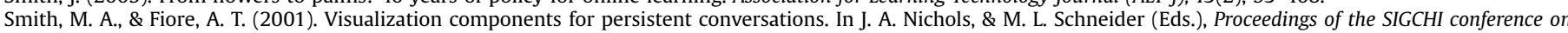
Human Factors in computing system (pp. 136-143). Maryland: ACM Press.

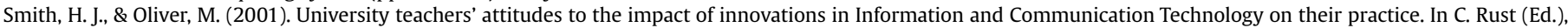
Proceedings of the 9th International Improving Student Learning Symposium (pp. 237-246). Oxford: Oxford Centre for Staff and Learning Development.

Weber, S. (2004). The success of open source. Cambridge, MA: Harvard University Press.

Weller, M. (2007). Virtual learning environments: Using, choosing and developing your VLE. Abingdon: Routledge.

Welser, H. T., Gleave, E., Fisher, D., \& Smith, M. (2007). Visualizing the signatures of social roles in online discussion groups. Journal of Social Structure, 8(2). 